\title{
ANÁLISIS DE LA RELACIÓN ENTRE CAPACIDAD DE CARGA FÍSICA Y CAPACIDAD DE CARGA PERCEPTUAL EN PLAYAS NATURALES DE LA ISLA DE MENORCA ${ }^{1}$
}

\author{
Francesc Xavier Roig i Munar \\ Director Técnico de Gestión Litoral \\ Consell Insular de Menorca
}

\section{RESUMEN}

Los espacios litorales situados en Áreas Naturales de Especial Interés (ANEI) de la isla de Menorca sufren una enorme presión turística y recreativa. El conocimiento de las pautas de uso sobre estos espacios, y la percepción de los usuarios, son aspectos primordiales para gestionar satisfactoriamente la demanda social a la que están sometidos, y para evitar o aliviar, en la medida de lo posible, impactos ambientales y sociales.

Palabras clave: litoral, ANEI, presión turística, Menorca.

\section{ABSTRACT}

In Menorca, some protected coastal areas included in the regional network of natural areas (ANEI, Natural Areas of Special Interest) support a huge recreational pressure derived from tourism. Knowing the user's habits on these areas as well as their perception constitutes a key tool to properly manage these coastal zones and their social request. It also can help to avoid or alleviate, as far as possible, environmental and social impacts.

Key words: coastal protected areas, ANEI, tourism pressure, Menorca.

\section{Introducción}

Los espacios litorales de la isla de Menorca, situados en Áreas Naturales de Especial Interés (ANEI) constituyen un importante recurso turístico y recreativo para la isla. La presión turística y recreativa que sobre ellos se da, concentrada durante el periodo estival, genera impactos ambientales y sociales de muy diversa índole, derivados estos de la sobrefrecuen-

1 Una primera versión de este trabajo fue presentada en el VIII Coloquio de Xeografía do Turismo, Lacer e Recreación, celebrado los días 7 y 8 de noviembre de 2002 en la ciudad de Santiago de Compostela, Galicia. 
tación de usuarios, tanto peatonal, rodada, como marítima, generación de importantes cantidades de residuos sólidos, fragmentación de hábitats naturales, y desencadenamiento de procesos erosivos, entre otros.

El conocimiento de las pautas de uso y frecuentación, así como los niveles de percepción de usuarios sobre estos espacios resulta una herramienta imprescindible para realizar programas y propuestas de gestión.

La imagen turística de la isla de Menorca está asociada en gran medida a las playas y calas vírgenes que encontramos a lo largo de su litoral. Sobre buena parte de estos enclaves se ubicaron núcleos turísticos entre los años 60 y 80 . Una vez completado el proceso inicial correspondiente al tardío desarrollo turístico de Menorca en relación al conjunto de las islas Baleares, amplias zonas litorales quedaron protegidas urbanísticamente con la aprobación de la Ley 1/1991 de Espacios Naturales Protegidos (LEN), que en el caso de Menorca protege urbanísticamente el $43 \%$ del su territorio, con un total aproximado de 30.500 Ha y 19 zonas declaradas ANEI.

Tradicionalmente los accesos a estas zonas litorales, actualmente protegidas, han sido complicados, debido a la escasez de pistas y caminos, y al hecho de que las existentes eran privadas o de uso exclusivamente agrícola-forestal, lo que ha provocado históricamente innumerables conflictos originados por el paso de visitantes en período estival (Roig, 2001). Paralelamente estos espacios naturales se han popularizado y su uso turístico y recreativo se ha masificado. La problemática que ello conlleva se agrava por el hecho que la protección otorgada por la Ley es únicamente urbanística, es decir, no comporta gestión alguna del patrimonio y recurso natural (Blázquez, 1994). Por otra parte la creciente capacidad de movilidad interna que han generado los nuevos hábitos turísticos, especialmente con el incremento exponencial del vehículo de alquiler, ha provocado que muchas de estas antiguas barreras hayan cedido ante la presión del turismo, provocando situaciones de masificación en estos espacios litorales.

\section{Objetivos del estudio}

El objetivo básico del estudio se ha basado en la determinación del alcance de los usos turísticos y recreativos sobre playas y calas situadas en el ANEI Me-14, Costa Sur de Ciutadella (Figura 1), basándonos en tres puntos;

1) Conocimiento de las curvas de frecuentación de usuarios de playa.

2) Establecimiento de la Capacidad de Carga Física de cada una de estas playas.

3) Análisis de percepción, mediante la determinación de la Capacidad de Carga Perceptual de usuarios de playa frente a la superación de los límites de Capacidad de Carga aconsejables para espacios litorales situados en ANEI.

Para el desarrollo del presente estudio se analizó la frecuentación de cinco espacios litorales que representan en gran medida la oferta de playa virgen de Menorca, siendo estos; Cala Macarella y Macarelleta, Cala en Turqueta, es Talaier y Arenal de Son Saura, valorando su Capacidad de Carga (CC) en las cinco playas y su Capacidad de Carga Perceptual (CCP) en dos de ellas.

En el presente estudio se hace una reflexión sobre ambos conceptos, que tienen como objetivo tratar de establecer cuándo comienza la congestión y estrangulamiento ambiental y su relación con el aspecto social del espacio receptor. 


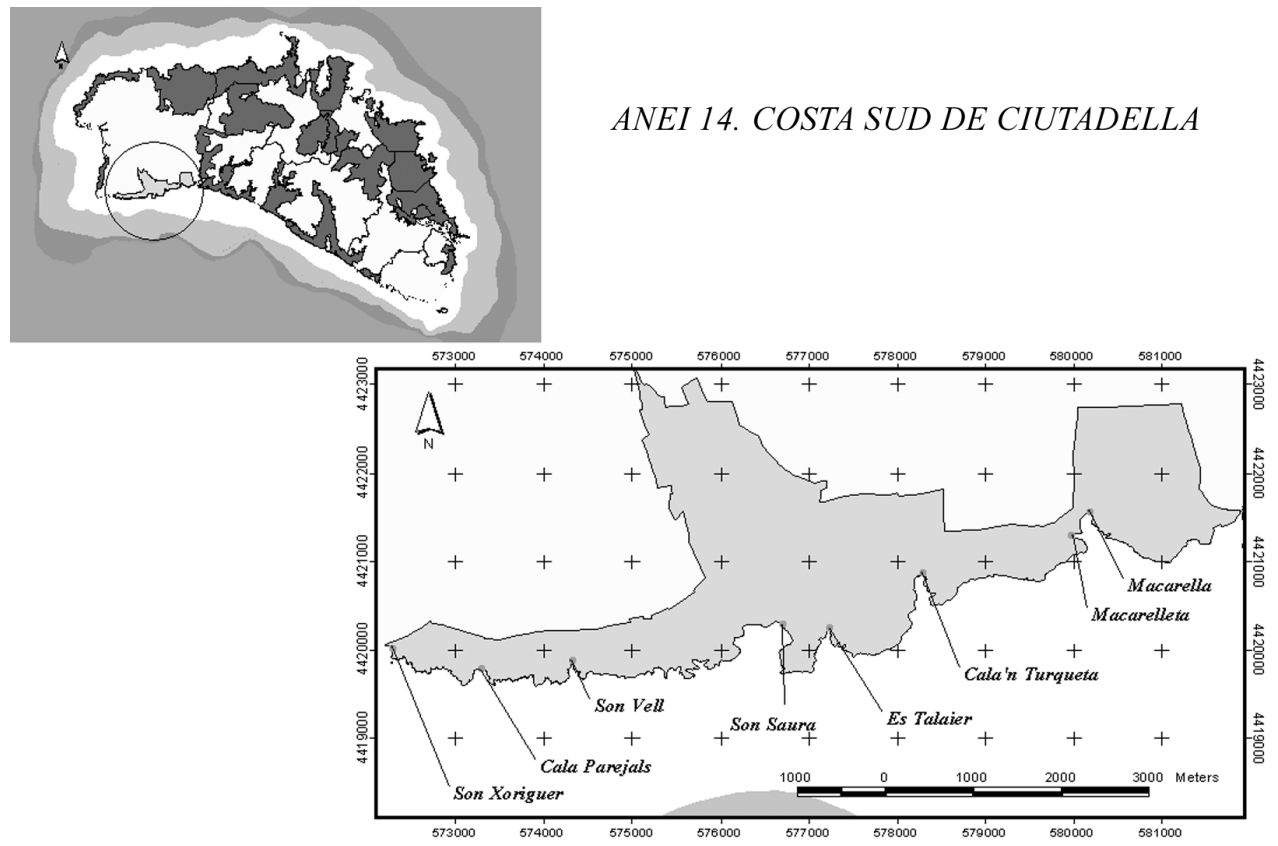

Figura 1. Área Natural de Especial Interés Me-14 (Costa Sud de Ciutadella).

Fuente: Elaboración propia.

En su sentido más convencional, el concepto de CC, como manera de expresar la carga ambiental sobre espacios naturales nació en la década de los 70. Este concepto era usado para considerar el potencial de uso mediante índices al desarrollo directo, existiendo dos campos muy diferenciados; a) manejo de recursos, y b) manejo del desarrollo. En este sentido cabe distinguir dos interpretaciones; la referida a densidad óptima de usuarios para el disfrute del espacio, y la referida a niveles de actividad que generan un deterioro físico del espacio receptor (Clark, 1990).

La CC referida al número máximo de personas que pueden ser acomodadas en un espacio ha sido comúnmente utilizado a partir de indicadores relativos a volumen y densidad de éste (Antón, 1997). Autores como O'Reilly (1986) la definen basándose en otros conceptos como psicológicos o perceptual, relacionada ésta con el límite en que la saturación del espacio receptor lleva a los usuarios a buscar nuevos destinos no masificados y de similares características. Según Holder (1988) la CC ha de ser definida como la densidad óptima para el bienestar de los propios usuarios. Holder opina que no existe una formula matemática que indique cuántos usuarios son suficientes y cuántos son demasiados para cada espacio. Él favorece la vigilancia constante de la tensión sobre los espacios receptores e impactos derivados de la frecuentación sobre estos.

Por lo que respecta a la CCP o Análisis de los Niveles de Satisfacción por parte de los usuarios presentes en espacios naturales, éste ha sido consignado generalmente como el principal producto resultante de una experiencia recreativa, y por tanto uno de los mayores objetivos fijados por los administradores de los recursos turísticos y recreacionales. En realidad la satisfacción es probablemente el indicador más comúnmente usado para referirse a 
la calidad de la experiencia turística y recreativa. Pero la determinación de los elementos que constituyen lo que entendemos como indicador de satisfacción han sido desde siempre una tarea dificultosa para los investigadores sociales.

Los autores Prost y Lime (1982) sugirieron que el concepto de satisfacción es equívoco y dificultoso para ser definido, no sólo en términos generales, sino también en el campo turístico y recreativo. La mayoría de los trabajos indican que los resultados pueden ser objeto de un número indeterminado de variables subjetivas y situacionales (Hendee, 1974), así como culturales y sociales. Los primeros estudios realizados en este campo propusieron modelos teóricos para la determinación de la CCP, basados en las relaciones entre satisfacción y densidad de usuarios. El modelo introducido por Alldredge (1972) asumía que el disfrute de la experiencia recreacional estaba en relación inversamente proporcional con el aumento de visitantes que podía experimentar una área. Otros autores (Kuss et alt., 1990), establecían la variable independiente del número de contactos con otros usuarios, la que influye sobre todos los grupos entre las que se cuentan el número de contactos esperados, el número de contactos ideales y finalmente el concepto de ambiente percibido y el esperado.

Basándonos en estos criterios expuestos podemos realizar una aproximación a la CC y la CCP de los espacios estudiados, ya que el conocimiento de pautas de uso y frecuentación sobre estos espacios litorales, conjuntamente con los problemas de percepción por parte de usuarios nos dará una información básica para la puesta en marcha de programas de gestión (Gómez-Limón, 1996), en este caso sobre espacio dinámicos y vulnerables.

\section{Metodología}

Para analizar la frecuentación de los visitantes de calas y playas situadas en el ANEI Me-14, y valorar su CC y CCP se siguió la siguiente metodología (Roig, 2000):

1. Elección de espacios litorales representativos de oferta de playa y cala virgen, situados en el ANEI Me-14. Se eligieron los cinco espacios ofertados como vírgenes, no urbanizados, de aguas cristalinas y situados en ANEI (Figura 1).

2. Muestreo de usuarios, realizado el domingo $13 \mathrm{y}$ el miércoles 16 del mes de agosto de 2000, coincidiendo con el período de máxima afluencia turística en la isla. Nos basamos en la elección de un miércoles y un domingo para poder obtener dos muestreos representativos de uso eminentemente turístico, el miércoles, y un uso mixto, turístico y recreativo, el domingo. Se contó el número total de personas sobre cada una de las playas y calas cada hora, desde las 10:00 h. a las 20:00 h.

3. Determinación de superficies en cada una de las playas y calas estudiadas para el establecimiento de la CC. Nos basamos en la zonificación establecida por usos en cada una de las playas (Roig, 2001):

1. Zona de uso intensivo o zona de swash: franja en donde se desarrollan juegos, entrada y salida del mar.

2. Zona de reposo: coincide con las zonas de concesión administrativa de servicios temporales de playa, se trata de la zona de playa que recibe un uso más intensivo. En este caso es la utilizada para determinar la CC.

3. Zona de tránsito: zona más lejana a la línea de costa, detrás de la zona de reposo, utilizada para la entrada, salida y búsqueda de un espacio en la playa. Morfológicamente se trata de la zona de playa alta comprendida entre playa y primeras morfologías de foredune. 
4. Análisis de la CCP, a lo largo de las dos jornadas de recuentos se realizaron encuestas a los usuarios presentes sobre las playas de Macarella y Es Talaier. Entre otras cuestiones, se les preguntaba si consideraban que en el momento de la encuesta había mucha gente en la playa. La pregunta era cerrada con posibilidad de responder si, regular o no. En base a la respuesta, la hora realizada y el aforo de usuarios en ese momento se determinó la CCP de cada playa, estableciendo tres franjas horarias relacionadas con la curva media de frecuentación obtenida, siendo estas; de 10:00 a 13:00 h., de 13:00 a 17:00 h. y de 17:00 a 20:00 h.

5. Análisis de diferentes productos comerciales y publicitarios; guías, folletos y postales, para relacionar el fenómeno de popularización de estas playas y calas situadas en el ANEI Me-14. Se ha analizado 43 productos diferentes mediante la realización de un muestreo aleatorio simple.

\section{Descripción geográfica del ANEI Me-14}

El Área Natural de Especial Interés Me-14 se encuentra situada en la costa sur del término municipal de Ciutadella, entre las urbanizaciones de Son Xoriguer, al Este, y Cala Galdana al Oeste. Tiene una extensión de 1.164 Has, distribuidas en una franja paralela a la línea de costa. En ella se encuentran situadas algunas de las playas y calas más visitadas de la isla, y que fueron catalogadas como playas de tipología B, situadas en espacios litorales naturales y con altos índices de visitación por los autores Juaneda y Roig (2001). El mayor encanto del área deriva del placer de poder visitar espacios litorales sin urbanizar, de aguas cristalinas y arenas blancas. Su paisaje es de relieve bajo con pequeños barrancos y acantilados calcáreos no superiores a los $40 \mathrm{~m}$ y calas poco profundas. La vegetación está constituida por masas de pino (Pinus halepensis) y garrigas (Quercus ilex), formando la masa forestal más extensa del sur de la isla. En la playa de Macarella y Macarelleta encontramos buenos ejemplos de pino y savina (Juniperetum phoenecera). Morfológicamente se trata de calas que han sido formadas por la erosión hídrica de los torrentes que en ellas desembocan y que cruzan el ANEI formando barrancos. En el caso de la playa de Son Saura, ésta constituye un ejemplo de sistema playa-duna relativamente bien conservado con la presencia de una zona húmeda, mientras que el caso de la playa de Macarelleta encontramos un sistema playa-duna remontante con fuertes procesos de erosión en sus morfologías, debido principalmente a la excesiva frecuentación de acampadas que en ella podemos encontrar en plena temporada estival.

Los accesos a estas playas y calas son rodados por caminos rurales y pistas forestales, algunos de ellos transcurren por barrancos, hasta pie de playa, hecho que facilita los procesos de degradación, como compactación y pérdida de suelo, degradación de vegetación, por la fuerte presión motorizada que sobre estos se da, y alteraciones de ecosistemas frágiles y endémicos propios de estos enclaves.

Las cinco playas estudiadas se encuentran a una distancia media de 10,5 km. del núcleo urbano más cercano, Ciutadella, y a $12,5 \mathrm{~km}$. del núcleo turístico de Cala Blanca, hecho que favorece una excesiva presión motorizada sobre estos espacios, ya que no existe ningún servicio de transporte público. Existe la posibilidad de acceder a cada una de ellas por el Camí de Cavalls, antigua ruta o sendero militar que une todo el litoral menorquín. Las playas y calas no disponen de ningún servicio, exceptuando los de socorro y primeros auxilios, únicamente la playa de Macarella cuenta con un servicio de chiringuito a pie de cala. La playa de Son Saura es de peaje, actualmente Menorca cuenta con tres playas de peaje. Estos peajes se establecen debido a que los propietarios de las fincas han decidido restringir el acce- 
so rodado con el cobro por la entrada o circulación al interior de sus fincas (Blázquez, 1999). Estas medidas de control del número de usuarios no tienen connotaciones conservacionistas, sino más bien obedecen a intereses de rentabilidad económica sobre espacios naturales altamente ofertados y demandados por usuarios, residente o visitantes, los cuales sus propietarios no tienen posibilidad de amortizar urbanísticamente por la aplicación de la LEN 1/1991.

\section{Resultados}

Seguidamente se muestran los resultados obtenidos, modelo de frecuentación de playas, la determinación de la $\mathrm{CC}$ en máxima ocupación y $\mathrm{CCP}$, en cada uno de los espacios litorales estudiados.

\section{Modelo de frecuentación de playas}

La representación del uso horario de playas y calas puede realizarse mediante curvas de ocupación o frecuentación, siendo ésta una metodología que puede utilizarse para estudios de planificación litoral. En el modelo obtenido los días de aforo (Figura 2) existe una clara concentración en el período de máximo uso de cada una de las playas, en donde las puntas se dan entre las 13 y las $17 \mathrm{~h}$, independientemente del día de aforo, exceptuando la playa de Macarelleta, la cual tiene una máxima de concentración a las $18 \mathrm{~h}$ del domingo día 13, debido a que en esta playa se encuentra una zona de acampada incontrolada y por tanto la afluencia puede

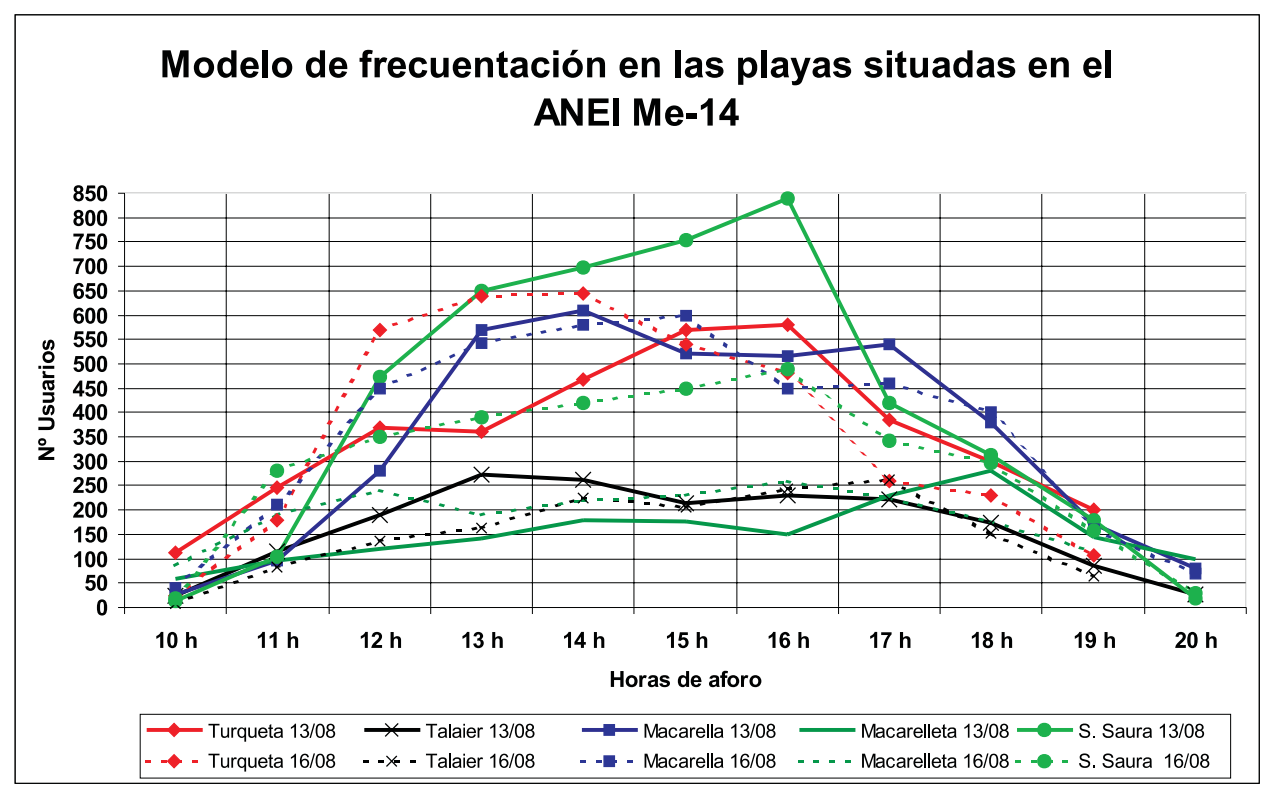

FIGURA 2. Modelo de frecuentación en las playas situadas en el ANEI Me-14.

Fuente: Elaboración propia. 
ser debida a los propios campistas. Así mismo podemos observar cómo el día 13, domingo, coincide mayoritariamente con el día de máxima afluencia de playa, exceptuando cala Turqueta y Macarelleta que muestran una frecuentación más elevada el día 16, miércoles.

Las curvas obtenidas obedecen a pautas de frecuentación de estancia media por usuario superiores a las 4,5 horas en la playa, obteniendo una curva en forma de campana, típica de playas naturales de la isla, al contrario que las curvas en forma de sierra con valles, obtenidas en playas de tipología urbana (Tejada, 2000). Muy posiblemente estos comportamientos obedezcan a la distancia que separa estas playas de los núcleos urbanos y turísticos, y una vez en la misma la estancia media sea mayor que en otros espacios litorales urbanos, debido al coste de desplazamiento en distancia y tiempo.

El modelo que hemos obtenido se ajusta parcialmente a los resultados obtenidos de la Encuesta a Turistas de 1989 (Price Waterhouse, 1990), en donde se estima que el 30’2\% de los entrevistados eligen el horario de uso de la playa de 12 a 16 horas, aunque cabe destacar que el estudio no especifica las tipologías de playas analizadas.

\section{Capacidad de Carga Física}

Una interpretación fordista del turismo de playas, según Vera et al. (1997), cita que éste podría analizarse mediante modelos que consideren la distribución espacial y temporal de los usuarios de la playa correlacionando la densidad de ocupación del espacio con factores tales como la capacidad de acogida del área receptora. En este caso aplicaremos la teoría de Holder (1988), referida a parámetros de densidad óptima. En nuestro caso al tratarse del estudio de una oferta de playa virgen es recomendable establecer criterios de ocupación de $25 \mathrm{~m}^{2} / \mathrm{usuario}$ en áreas de reposo, pero al ser Menorca una isla con un sector turístico muy estacional y centrado en los meses de verano, rebajamos la superficie óptima máxima establecida a $15 \mathrm{~m}^{2} / \mathrm{usuario}$ en cada una de las playas estudiadas (Roig, 2000).

Para realizar los cálculos de $\mathrm{CC}$ se ha tomado como base la superficie de la playa, área de reposo de cada una de ellas y dividida ésta por el número de visitantes presentes cada hora. El resultado ha sido la representación de la $\mathrm{CC}$ en el momento de máxima ocupación de cada una de ellas en los días de muestreo (Figura 3), esta máxima ocupación coincide con las franjas horarias de uso comentadas anteriormente.

En la Figura 3 podemos observar cómo las playas se encuentran sobresaturadas en su uso, no llegando a la capacidad óptima establecida y recomendada por usuario en cuatro de estas playas. Destaca muy por encima de la media la playa de Son Saura, la cual cumple con las expectativas de playa natural en los dos días de muestreo, llegando a superar los $15 \mathrm{~m}^{2} / \mathrm{usua}-$ rio recomendados. Esta causa puede ser debida posiblemente que se trate de un espacio de acceso controlado por peaje con una pista agroforestal en mal estado, y con una longitud superior a los 4,5 Km. Las demás playas estudiadas no superan los $5 \mathrm{~m}^{2} / \mathrm{usuario}$ establecidos en playas de carácter urbano, como es el caso de Son Xoriguer y cala'n Porter las cuales obtuvieron una media de $8 \mathrm{~m}^{2}$ /usuario (Roig, 2001), y que reúnen todas las «comodidades» al usuario, tanto en servicios, transporte, como en proximidad a núcleos urbanos y turísticos.

A lo largo de los días de muestreo sólo se obtienen valores de CC satisfactorios en las primeras y últimas horas del día. Obtenemos en la primera hora del domingo una CC superior a los $15 \mathrm{~m}^{2} / \mathrm{usuario}$ en las playas de Talaier, Macarella y Son Saura, mientras que el miércoles la CC óptima estimada la encontramos en las tres playas citadas y Turqueta. Las últimas horas de la tarde encontramos valores de $\mathrm{CC}$ en todas las playas, triplicando en algunas ocasiones los valores aconsejados en este estudio. En el caso de Macarelleta no se 


\section{Análisis de la Capacidad de Carga en máxima ocupación por playas}

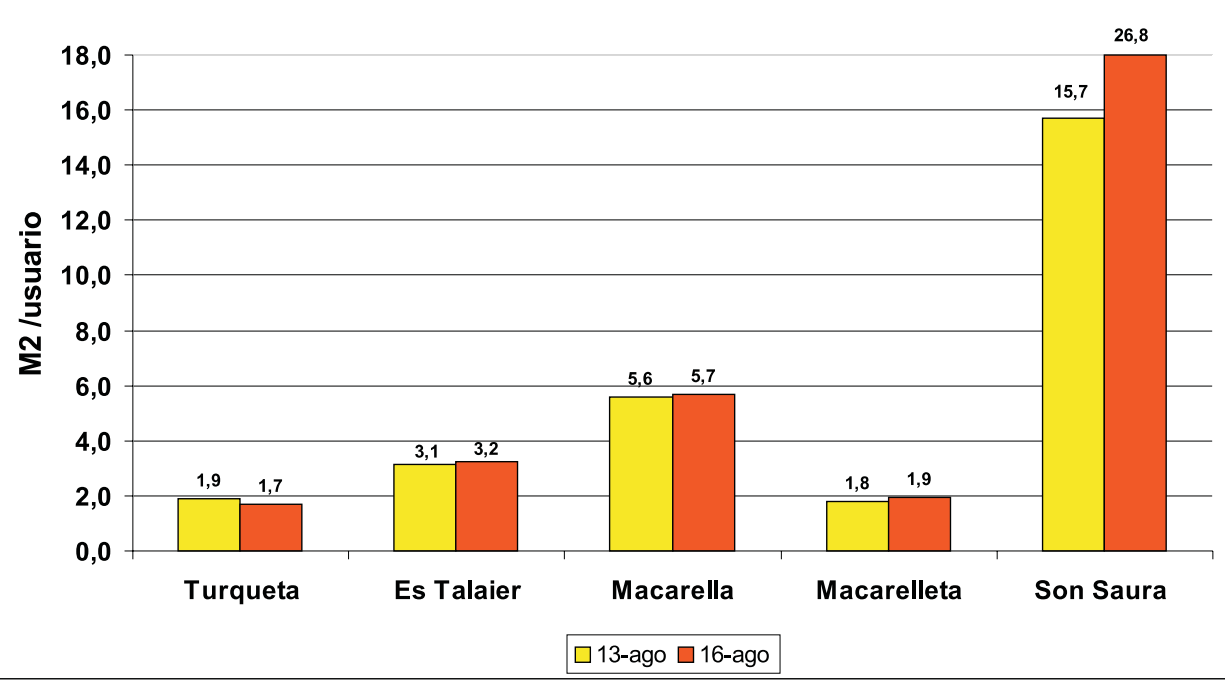

FiguRA 3. Análisis de Capacidad de Carga Física en máxima ocupación diaria de cada una de las playas. Fuente: Elaboración propia.

ha detectado en ninguna franja horaria una CC superior a los $5 \mathrm{~m}^{2} / \mathrm{usuario}$, esto se debe a que la playa se encuentra ocupada continuamente por campistas.

Para explicar este fenómeno de sobrefrecuentación por la popularización de playas y calas situadas en espacios naturales mediante la publicitación y comercialización del producto litoral, se han analizado algunos de estos productos que favorecen este uso. Se efectuó un recuento de folletos, postales y guías turísticas en establecimientos de las localidades de Maó y Ciutadella, núcleos urbanos más importantes de la isla. Se anotó las veces que aparecían estas playas como imagen publicitaria. En cada una de las imágenes observadas se pudo apreciar como estas reflejan la situación de espacios litorales vírgenes y con pocos o ningún usuario presentes en la imagen, así como la falta de embarcaciones fondeadas en las mismas, dando lugar a la motivación de ser visitada por el observador, y por ende, inducir a la excesiva frecuentación de estos espacios situados en ANEI.

En la Figura 4 se puede intuir como de una forma inconsciente el usuario se ve atraído por estos productos que favorecen situaciones de $\mathrm{CC}$ inferiores a las recomendadas. Del análisis destacan las playas de Macarella y Turqueta que aparecen publicitadas en porcentajes superiores del $60 \%$ y el $49 \%$ respectivamente en el conjunto de los productos. Destacan los valores obtenidos en el análisis de guías turísticas y folletos, un total de siete y cinco respectivamente, en donde estos espacios aparecen en la mayoría de las guías, con valores superiores a $\operatorname{los} 85 \%$ en conjunto, siendo Macarella y Turqueta las que se publicitan en un $100 \%$, así mismo estas dos playas también aparecen en un $100 \%$ en folletos. Por lo que respecta al análisis de las postales, estas dos playas son también las que más aparecen en los productos. 
De este modo obtenemos la sobreexplotación del espacio publicitado como receptor desde el punto de vista físico e indirectamente desde el punto de vista social o perceptual, dando como resultado la sobresaturación de visitantes y la explotación como imagen turística del mismo. Este uso masivo constatado con el análisis de la CC (Figura 3), ofrece al usuario una disminución de calidad en la experiencia recreativa y turística desde el punto de vista del participante (Glyptis, 1991), como podremos observar más adelante.

\begin{tabular}{|c|c|c|c|c|}
\hline Playa & Guías turísticas & Folletos & Postales & $\begin{array}{c}\text { Total } \\
\text { publicitado }\end{array}$ \\
\hline Macarella & $7 / 7$ & $5 / 5$ & $14 / 31$ & $\mathbf{2 6 / 4 3 ( 6 0 . 4 \% )}$ \\
\hline Son Saura & $6 / 7$ & $3 / 5$ & $10 / 31$ & $\mathbf{1 9 / 4 3 ( 4 4 . 2 \% )}$ \\
\hline Talaier & $5 / 7$ & $2 / 5$ & $6 / 31$ & $\mathbf{1 3 / 4 3 ( 3 0 . 2 \% )}$ \\
\hline Turqueta & $7 / 7$ & $5 / 5$ & $21 / 31$ & $\mathbf{2 1 / 4 3 ( 4 8 . 8 \% )}$ \\
\hline
\end{tabular}

FIGURA 4. Análisis de diferentes productos que publicitan los espacios litorales analizados. Fuente: Elaboración propia.

\section{Capacidad de Carga Perceptual}

El establecimiento de la CCP se realizó mediante encuestas de percepción en las playas de Es Talaier y Macarella. Estas encuestas realizadas a lo largo del día se han relacionado a partir de los resultados obtenidos de frecuentación diaria de cada uno de estos espacios. De las curvas observadas por playas se tomaron como representativas tres franjas horarias que abarcan la jornada; de 10 a 13:00 h, de 13:00 a 17:00 h y de 17:00 a 20:00 h, en cada una de estas franjas horarias se determinó el porcentaje de usuarios que consideran que la playa presenta mucha ocupación (es decir que contestaron si a la pregunta formulada), y se representa en porcentajes respecto al total de encuestados por cada una de las franjas horarias. De este modo podemos observar (Figura 5) como la CCP se encuentra relacionada con las puntas de ocupación, tal y como sugería Alldredge (1972).

Observamos como la punta de CCP es, en la mayoría de ocasiones, inversa a las puntas de frecuentación obtenidas en cada una (Figura 1). Esta disminución del CCP en el caso de Macarella se refleja en la curva de máxima afluencia en la segunda franja horaria del domingo, con valores de insatisfacción medios en usuarios del 33,3\% en toda la jornada. Mientras que el día 16 la franja con una CCP mas baja, el 60\%, se sitúa en la primera franja horaria del día, con una media en la jornada del $40 \%$ de insatisfacción de usuarios.

La playa de es Talaier supera el 63\% de insatisfacción el domingo día 13 en la última franja horaria, y presenta una media de insatisfacción del 59,3\%. El miércoles día 16 presenta una media del $90 \%$ de insatisfacción en su última franja horaria y una media del $66 \%$ de insatisfacción a lo largo de toda la jornada, hecho que se ajusta a los valores obtenidos de $\mathrm{CC}$, representados en la Figura 3.

Los modelos obtenidos de CCP en cada playa ejemplifican una pérdida de experiencia recreativa y una disminución del grado de satisfacción de usuarios asociada a la elevada frecuentación del espacio receptor. El grado de insatisfacción constatado a lo largo de los dos días en las dos playas es superior al $50 \%$. 
De los resultados obtenidos sorprende el día 16, miércoles, de uso eminentemente turístico, en donde los resultados muestran una mayor satisfacción el domingo, de uso mixto, en cada playa, al contrario del esperado. Los resultados obtenidos en la CCP pueden generar una sucesión y combinación de impactos que van más allá de la propia insatisfacción del usuario, ya que esta insatisfacción y saturación puede dar lugar a percibir de una forma más reforzada el efecto de otros impactos de carácter ambiental.

\section{Conclusiones}

Los cinco espacios analizados representan situaciones de sobrefrecuentación por la falta de gestión de cada uno de ellos.

Las situaciones detectadas en este trabajo pueden dar lugar a un incremento excesivo del deterioro de cada uno de estos espacios, ya que la superación de las CC's establecidas para sistemas litorales situados en ANEI's puede dar lugar a la búsqueda, una vez en el espacio receptor y habiendo una $\mathrm{CC}$ superior a la esperada, de espacios de reposo situados en los entornos de las playas, desencadenando nuevos procesos de fragmentación y degradación de los espacios naturales adyacentes a estos, ya sea desde el punto de vista morfológico como botánico.

La puesta en marcha de medidas de gestión y conservación de su uso público puede mejorar el uso turístico-recreativo.

Entendemos que el desarrollo del turismo ha de ser compatible con el medio natural, para asegurar la perdurabilidad del recurso como espacio y la calidad del visitante. Los estudios de CC y CCP son un instrumento necesario en esta línea. Creemos que la metodología utilizada, basándonos en aforos en miércoles y domingos, así como el establecimiento de criterios de superficies de reposo para cada una de las playas pueden ser una buena herramienta para conocer las pautas de comportamiento en espacios turísticos, y posteriormente realizar medidas de gestión sobre ellos.

Ante esta situación detectada no parece lógico ofertar de forma convencional y masiva este tipo de playas y calas, ya que el conjunto de playas no urbanizadas de Menorca y situadas en ANEI's representa en su totalidad 13,5 km lineales del litoral protegido de la isla, con una superficie útil de 14 ha, el $23 \%$ de la superficie total de las playas de la isla. Así pues no parece sensato sacrificar con los volúmenes de frecuentación detectados, la propia imagen de la isla, poniendo en peligro sus valores más emblemáticos, aspecto que desde nuestro punto de vista, debería ser tenido en cuenta por las administraciones de la isla, relacionadas tanto con la actividad turística, como de medio ambiente.

\section{Agradecimientos}

La información utilizada en este trabajo pertenece al Área de Medio Ambiente y al Área de Cooperación Local del Consell Insular de Menorca, procedente de los resultados obtenidos dentro de la Campaña de Educación, Información y Concienciación de usuarios de playa, incluida en el Plan de Gestión Integral del Litoral de la isla de Menorca, temporada estival 2000. El autor agradece al Consell Insular de Menorca y a las dos Consellerias la autorización para el uso, difusión y publicación de las mismas. 

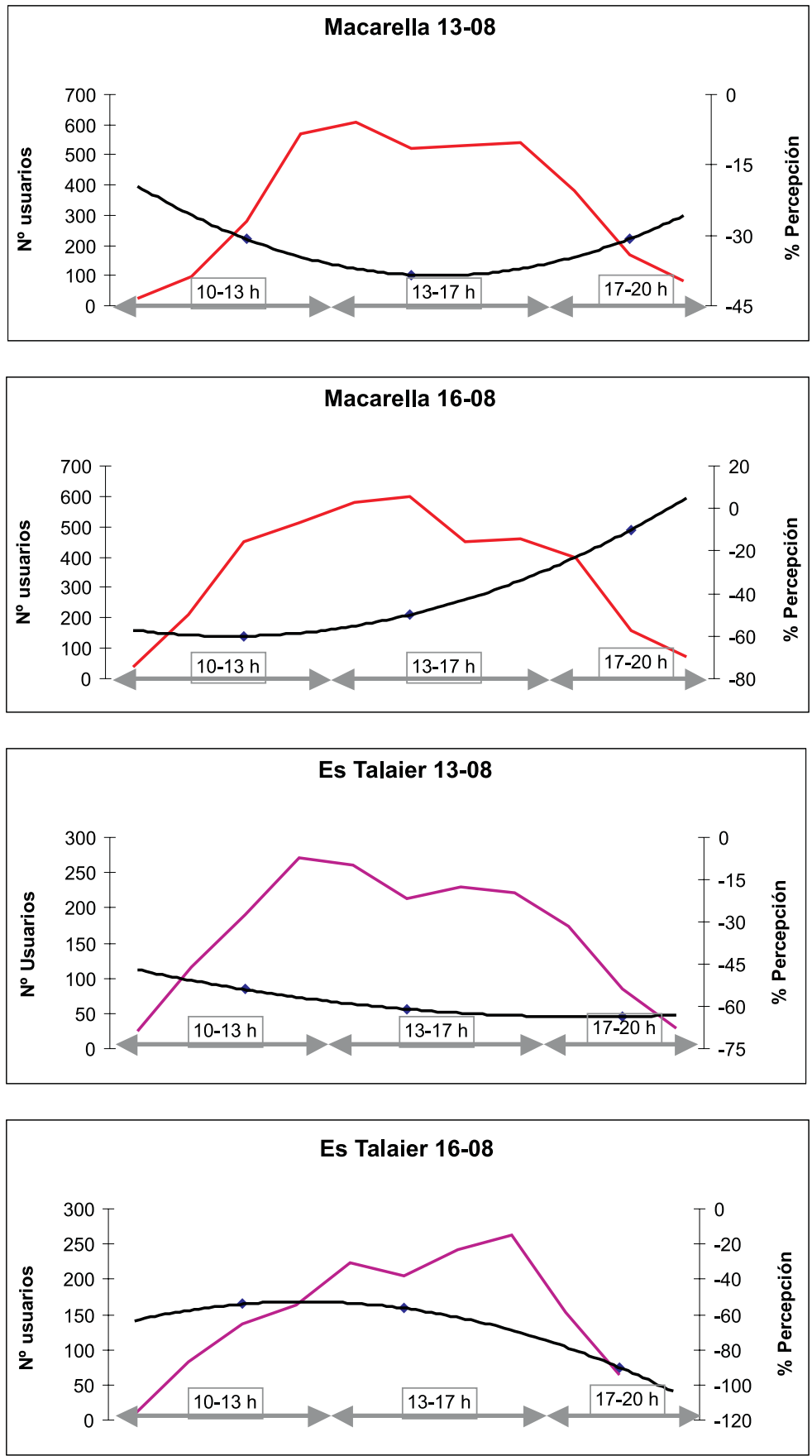

GrÁfICA 5. Análisis de Capacidad de Carga Psicológica diaria de las playas de Macarella y es Talaier. Fuente: Elaboración propia. 


\section{Bibliografía}

ALLDREDGE, R. (1972): «Some capacity theory for parks and recreation areas. Trends (Oct-Dec) pp. 20-29.

ANTÓN CLAVÉ, S. (1997): «Métodos y técnicas para la planificación turística del territorio». En J. Oliveras y S. Antón (Eds.) (1997): Turismo y planificación del territorio en la España de fin de siglo. Tarragona: GET, Univ. Rovira i Virgili pp. 5-44.

BLÁZQUEZ, M. (1994): «La platja d'es Trenc, un exemple d'espai sotmés a forta pressió recreativa informal, amb superació dels llindars de capacitat de càrrega ecològica $\mathrm{i}$ recreativa.» XIII Jornades d'Estudis Locals. Institut d'Estudis Balearics, Palma Mallorca.

BLÁZQUEZ, M. y ROIG, M. (1999) «L'abast de l'excursionisme a Mallorca» en Bolletí de Geografia Aplicada, vol. 1, pp. 11-32. Palma de Mallorca.

CLARK, J.R. (1990): Carrying capacity: the limits to tourism. University of Miami. Rosentiel Scool of marine and atmospheric Sciences. (presented in the Congress on Marine Tourism, East/West Conference Center, Univ of Hawaii, Honolulu, May 23-29).

GÓMEZ LIMÓN, J. (1996). Uso receativo de los espacios naturales de Madrid. Frecuentación, caracterización de visitantes e impactos ambientales. Consejeria de Medio Ambiente y desarrollo regional, Comunidad de Madrid.

HENDEE, J.C. (1974): «Wildernees Managament». USDA Forest Service. Miscellalenous publication 1365. Washington, D.C.

HOLDER, J.S. (1988). «The pattern and impact of tourism on the environment of the Caribean» en F. Edwards, Ed. Enviromentally Sound Tourism in the Caribean. University of Calgary, Canada.

JUANEDA, J. y ROIG i MUNAR, F. X. (2001). «El pla de neteja integral de l'illa de Menorca com a eina de gestió ambiental». En Geografía y Territorio. El papel del Geógrafo en la escala local. Ed. Bàzquez, M, et alt. Pp. 225-232. Universitat de les Illes Balears.

KUSS, F.R., GRAEFE, A.R. \& VASKE, J.J. (1991): «Visitor impact managament» En Review of research (Vol. I), Washington, D.C., National parkc and conservation Association, $256 \mathrm{pp}$.

O'REILLY, A.M. (1986). «Tourism carrying capacity: concepts and issues». Tourism Managament, 7 (4): 254-258.

PRICE WATERHOUSE (1990). «Capacidad potencial de absorción de turismo del litoral español». Ed. Secretaría General de Turismo. Madrid. 127 pp.

PROST, D., LIMe, D. (1982). «How satisfiying is satisfaction researh? A look at where we are giong» In Forest and river recreation: researh update pp. 124-133. University of Minnesota.

ROIG i MUNAR, F.X. (2000). «Análisis de la Capacidad de Carga en los espacios litorales, calas y playas, situados en áreas naturales de especial interés de la isla de Menorca» en Turismo y transformaciones urbanas en el siglo XXI. Ed. Fernández Gutiérrez et alt. pp. 325-236. Universidad de Almería.

ROIG i MUNAR, F. X. (2001): «Model de frequentació litoral dels espais litorals situats en Àrees Natural d'Especial Interés Me-3 de Menorca». En Geografia y Territorio. El papel del Geógrafo en la escala local. Ed. Blázquez, M, et alt. Pp. 279-286 Universitat de les Illes Balears.

TEJADA, M. (2000). «Capacidad de carga turística. Un modelo de los efectos territoriales y ambientales del uso turístico en el litoral. Caso de estudio de la playa de isla Canela, Ayamonte (Huelva). Memoria de Investigación Universidad de Sevilla, Departamento de Geografía, 157 pp. Inédita.

VERA, J.F. (coord.) et al. (1997). Análisis territorial del turismo. Una nueva geografía del turismo. Ariel. Barcelona. 443 pp. 